\title{
RADIO PROGRAMMING FOR YOUTH UPTAKE IN AGRICULTURE IN NYANZA REGION, KENYA
}

\author{
Andrew Kasera, Okello \\ Szent István University, Faculty of Economics and Social Sciences, Gödöllő, Hungary \\ E-mail: kasry2002@yahoo.com
}

\begin{abstract}
Youths participation in agriculture is at a lower level yet still decreasing worldwide (Proctor and Lucchesi 2012); this trend is the same for Nyanza region of Kenya. this study interogate youths in this region to understand how radio can be used to encourage their participation in agriculture. Radio is a vital tool in information disermination as it reach a large number of people including those in rural areas (Akugizibwe et al, 2011). This study was done in four Counties of Nyanza region namely Siaya, Kisumu, Homabay and Kisii. The specific objectives of this study are i) To investigate reasons why most youths do not participate in agricultural production in Nyanza region. ii) To assess why current agricultural radio-programmes do not influence youths' participation in agriculture and, iii) To suggest better ways which radio can disseminate agricultural information to influence youths' participation in agriculture. In summary, the study found out that; i) the major reasons why most youths do not participate in agricultural production in the region is that they consider it to be high labor intensive, low income generation activity and also agriculture to them is seen as belongs to failures in life among others. ii) In assessing why current agricultural radio-programmes do not influence youths' participation in agriculture, the study found out that there were challenges in the radio listenership of agricultural programs majorly caused by the inconvenient time of airing agricultural programmes on radio, other competing programmes in radio which were of more interesting to youths than agricultural programmes, high cost of buying batteries especially those in the rural areas among others which are explained in this paper. iii) In suggesting ways through which radio can disseminate agricultural information better to influence youths' participation in agriculture, the study found out that repeat of agriculture programmes at different times of the day would be the best way to solve the challenge followed by involvement of the youths in content making which would enable the programmes to be friendly to the youths, the third solution to the listenership challenge was the use of agritips between other radio programme which are interesting to the youths as this would draw their attention and make them be interested in the full programes on agriculture. There are also other ways proposed to improve listenership of the youths to agriculture radio programmes covered within this study.
\end{abstract}

\section{Introduction}

Agriculture is the backbone of the Kenyan economy. It is the single most important sector in the economy, contributing approximately $25 \%$ of the GDP, and employing $75 \%$ of the national labor force (Republic of Kenya 2005). Over $80 \%$ of the Kenyan population live in the rural areas and derive their livelihoods, directly or indirectly from agriculture. Given its importance, the performance of the sector is therefore reflected in the performance of the whole economy. The development of agriculture is also important for poverty reduction since most of the vulnerable groups like pastoralists, the landless, and subsistence farmers, also depend on agriculture as their main source of livelihoods. Growth in the sector is therefore expected to have a greater impact on a larger section of the population than any other sector. 
The development of the sector is therefore important for the development of the economy as a whole (Patrick and Rosemary, 2006). Youth unemployment is a serious development issue in Kenya. It is estimated that $64 \%$ of unemployed persons in the Country are youth. Interestingly only $1.5 \%$ of the unemployed youth have formal education beyond secondary school level and the remaining over $92 \%$ have no vocational or professional skills training and the majorities are found in the rural areas of Kenya. Due to inadequate opportunities in rural areas the tendency is the migration to urban centers to look for opportunities.

As mentioned above, Kenyan economy heavily depends on Agriculture, which is basically rural-oriented sector. Surprisingly, Kenyan agriculture is still labor-intensive thus the outmigration of young and productive labor force from rural to urban centers has a direct negative impact on agricultural production hence job creation in other sectors which are directly or indirectly linked to the agriculture sector are definitely reduced. A strategy of rolling back rural -urban migration by creating opportunities for employment and access of livelihoods would have a positive spiral effect on Kenya economy.

Every country of the world is certainly striving to be food secured. Nyanza, a region in Kenya situated in the Western part, is a net importer of food despite having relatively good agricultural land and favorable weather conditions. This is mainly because only women and children are left to undertake agricultural activities in the region. Men and youths are mostly involved in leisure activities which do not add value to the families economically (GoK, 2009). This has contributed to incidences of hunger in this region as food produced by women and their young children is not enough for the whole family.

There are several channels available for use to dispatch agriculture information to farmers. These include extension agents, individuals, farmers-to-farmers contact, print media and electronics media. Examples of print media are newspapers, magazines, newsletter, pamphlet and posters, while on the other hand, examples of electronic media includes Radio, television, and film schedules and films trips. Among all those channels, radio is found to be the most important means of communicating agricultural information to the rural farmers. It is one of the broadcast medium which the rural populations are very familiar with and which almost all experts identified to be the most appropriate for rural emancipation programme. This is because radio beats distance and has immediate effect on farmers. Furthermore, radio is favored as a medium of communication in rural communities because of the advantages ascribed to it, inform of transcending the barrier of illiteracy and demanding less intellectual exertion than the print media messages (Akugizibwe et al, 2011).

This study paper explains how radio programming can sensitize youths to participate in farming business hence more development in rural areas.

The goal of this study is to enhance rural development by influencing youths' participation in agricultural production through better collection, packaging and dissemination of timely agricultural extension messages to youths through radio.

The specific objectives of this study are;

1. To investigate reasons to why most youths do not participate in agriculture within Nyanza region of Kenya.

2. To assess why current agricultural radio-programmes do not influence youths to take up agriculture as an economic activity. 
3. To suggest better ways through which radio as a communication media can be used to disseminate agricultural information to influence youths' participation in agriculture.

\section{Material and methods}

This study was done in Nyanza region of Kenya. This region was chosen because it has relatively good agricultural land and favorable weather conditions yet the region still face periodic hunger due to over reliance on women to produce food for the family while youths in most cases do not engaged in agriculture as they consider anybody practicing agriculture to be a failure in life (UNDP-Kenya Report, 2009). The research employed the use of both primary and secondary data. The secondary data was sourced from desktop research, on the other side a survey by use of structured questionnaire was conducted to farmers in Nyanza region of Kenya in order to get the primary data needed for this study. This study used an ex-post facto research design via a cross sectional survey as the study used naturally occurring treatments on subjects having a self-selected level of the independent variables. The manifestations of the effect of the independent variables on the dependent variable had already occurred and the researcher, therefore, did not manipulate them. Cross sectional survey was used instead of longitudinal survey because of limited time and finance for carrying out the study. In addition, the study sought to investigate the relationship between the dependent variable and the independent variables (Kathuri and Pals, 1993).

Nyanza region has 6 counties. It is located 385 kilometers north of Nairobi. It has a total area of about $32912 \mathrm{~km}$ out of which $15979 \mathrm{~km}$ is under water majorly Lake Victoria. It is bordered by Western Province to the North, Rift valley province to the East, Republic of Tanzania to the South and Republic of Uganda to the West. The data for this study were collected in four Counties namely Siaya, Kisumu, Homabay and Kisii. A total of 20 questionnaires were

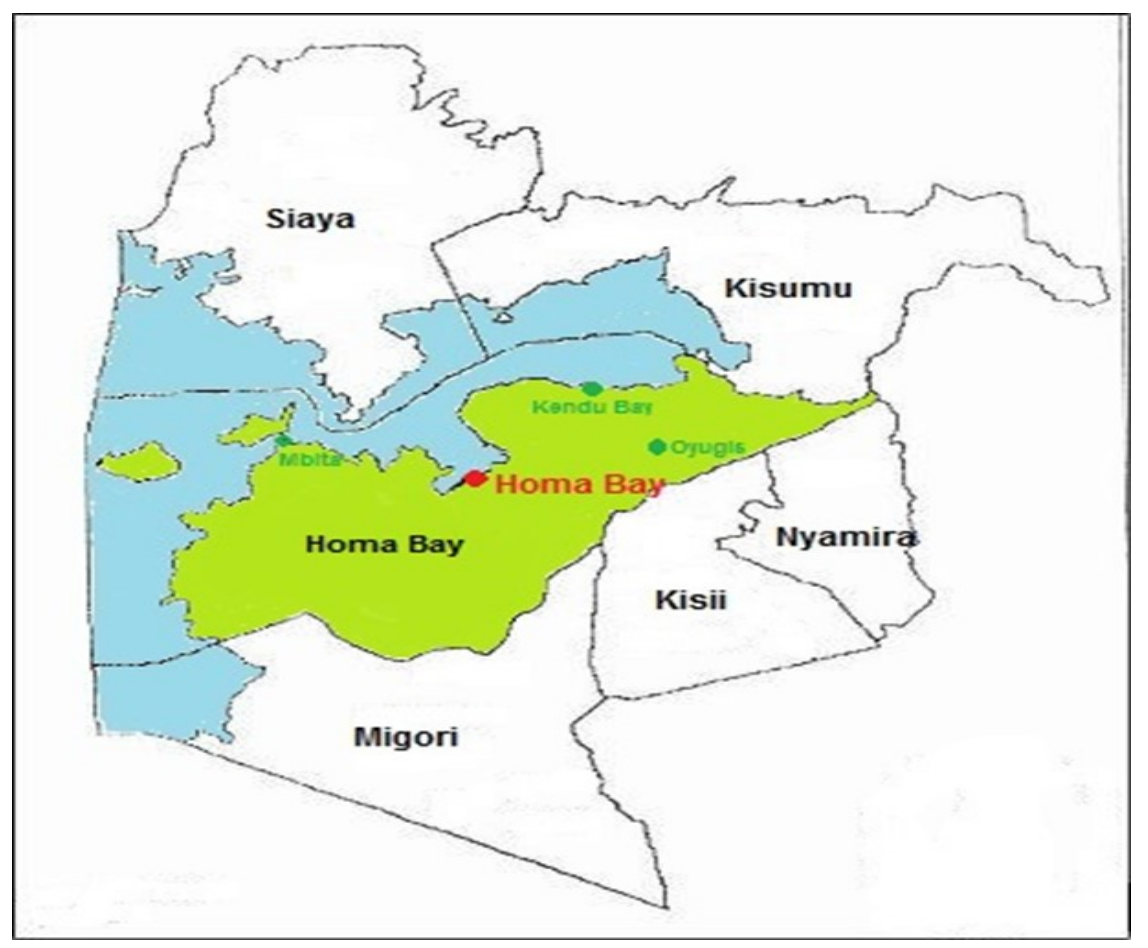

Map 1: The map of Nyanza region showing its six Counties

Source: http//wikimedia.org/wiki/File:Nyanza administered to youths in each county hence giving a total of 80 questionnaires administered. The study considered youths to be people of age between 18 year to 35 years old as per the Kenya census report (GoK, 2009). 


\section{Results and discussion}

The data used for this study was collected from a study sample of 80 respondent distributed in four Counties of Nyanza region. The sex of the respondents was 40 Male and 40 female as shown in Table 1 beside. The Counties used for the study were; Siaya, Kisumu, Kisii and Homabay. These Counties; Siaya, Kisumu and Homabay lies along Lake Victoria, Kisii is in the highlands which receives high rainfall and is also very potential Table 1: Sex of respondent

\begin{tabular}{|c|l|l|l|l|}
\hline & $\begin{array}{l}\text { Frequ } \\
\text { ency }\end{array}$ & Percent & $\begin{array}{l}\text { Valid } \\
\text { Percent }\end{array}$ & $\begin{array}{l}\text { Cumulative } \\
\text { Percent }\end{array}$ \\
\hline Valid Male & 40 & 50.0 & 50.0 & 50.0 \\
Female & 40 & 50.0 & 50.0 & 100.0 \\
Total & 80 & 100.0 & 100.0 & \\
\hline
\end{tabular}
for agriculture production.

\section{Reasons to why most youths do not participate in agricultural production}

This study revealed that there are several reasons to why youths in Nyanza region of Kenya do not take up agriculture as an economic activity; this is as shown in Figure 1 below.

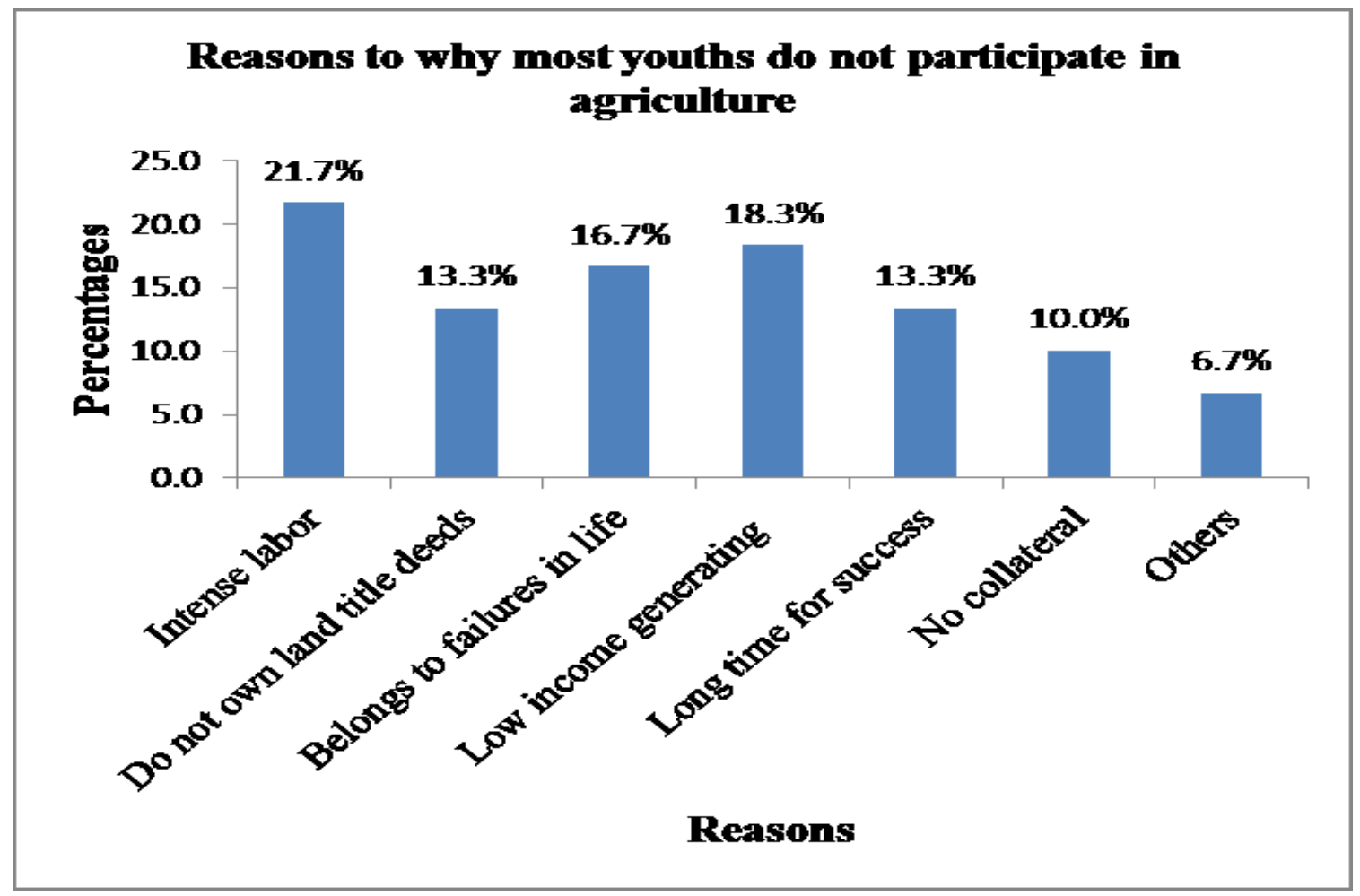

Figure 1. Reasons to why most youths do not participate in agriculture

Source: own editing, 2013.

Among the reasons stated, high labor intensity in agricultural production formed the major reason to why youths do not engage in agriculture, with $21.7 \%$ of the respondents saying the same. Low income generation from agricultural activities followed up at second most reason, while at third position with a percentage of 16.7, the study revealed that youths consider agriculture to be an activity of failures in life. 
Talking to youths in this region on the same they added that in primary and secondary schools, agricultural activities for example slashing ploughing, and even weeding are used as punishment when students do mistake hence they grow up hating agriculture and seeing it as a punishment. At $13 \%$ there is a tie of youths do not own land title deeds and agricultural production takes long time for its returns to be realized. For not having the land title deeds it means that the youths are not able to make long-term investment on the pieces of land that they are using, this discourage youths engagement to meaningful agricultural production. Youths proved to be more interested in those activities that their payback period is short as opposed to agriculture where they need to invest then take longtime before they harvest or sale their livestock. At 10\%, the study revealed that youths do not participate in agriculture effectively as they do not have collateral to use for bank loans. From many literature, this should be one of the major reasons for youths not participating in agriculture but for the case of Nyanza region as it came up during the study, it was not a major issue because many people in this region seemed to be scared of taking bank loans to make capital developments, This is a major area that need sensitization if this community is to develop. The other issue was that most of production is manual and people use hoe to undertake most of the ploughing, to the youths, they would prefer to participate in a mechanized system of production.

\section{Reasons why current agricultural radio-programmes do not influence youths to take up agriculture as an economic activity}

The effectiveness of a radio programme is the listenership of the programme. If people listen to programmes, they will be informed hence, they will most likely implementing what they have learnt (Woodard, 2012). With this background, it was revealed during this study that reasons why the current agricultural radio programmes do not influence youths' participation in agriculture were majorly issues which hinders youths from listening to the agricultural programmes on radio. Figure 2 above shows some of these challenges. The first major hindrance of current agricultural radio program to influence youths' participation to agriculture is the inconvenient time of airing agricultural programmes on radio, most of the youths said that they are only able to listen to radio at night while most of the agricultural programmes are aired in the morning hours or during the day when they are not next to radio or they are busy doing other things. The inconvenient time of airing agricultural programme constituted $21 \%$ of the responses and is also the highest most reason for youths not able to participate in agriculture as a result of radio programme. The second most challenge at $14 \%$ was other competing programmes in radio which are more interesting to youths than agricultural programmes. It was followed at $13 \%$ by airing information at wrong seasons, the study found out that in most cases the programmes aired during the agricultural session are not the information needed at that time of the season, an example given was information on how to harvest when everyone is ploughing, this means that as much as people will listen to the information on radio, when it come to the time of harvesting everyone would have forgotten about what was taught thus becomes ineffective.

The study also revealed that most of the youths especially those that live in rural areas where there is no power felt that the cost of buying batteries was high for them thus they could not listen to agricultural radio programmes most often. Lack of interest of the youths in agricultural production also formed a big reason to why youths do not listen to agricultural programmes on radio. By not listening to them therefore, the youths could not gain from them. It was also found at $8 \%$ that some youths do not listen to agricultural programmes as other family members control the channel that the family has to listen to especially in cases where the household own only one radio. 
In these cases, the respondents said elder members of the family decides on channels to be listen to thus deny youths chance to listen to agriculture programme. Poor network coverage was also raised as a challenge to listening to radio programs as there are areas where transmission of some of the radio channels does not reach. As shown in Figure 2 above, the other impediments to listening to agricultural radio programmes is use of difficult scientific words that most of the youths cannot comprehend, then finally the language barrier also impede some youths from following agricultural programmes on radio well, they said that it is better if it is aired in the local radio stations where they will hear the programme in the local language, this was at $4 \%$ of responses.

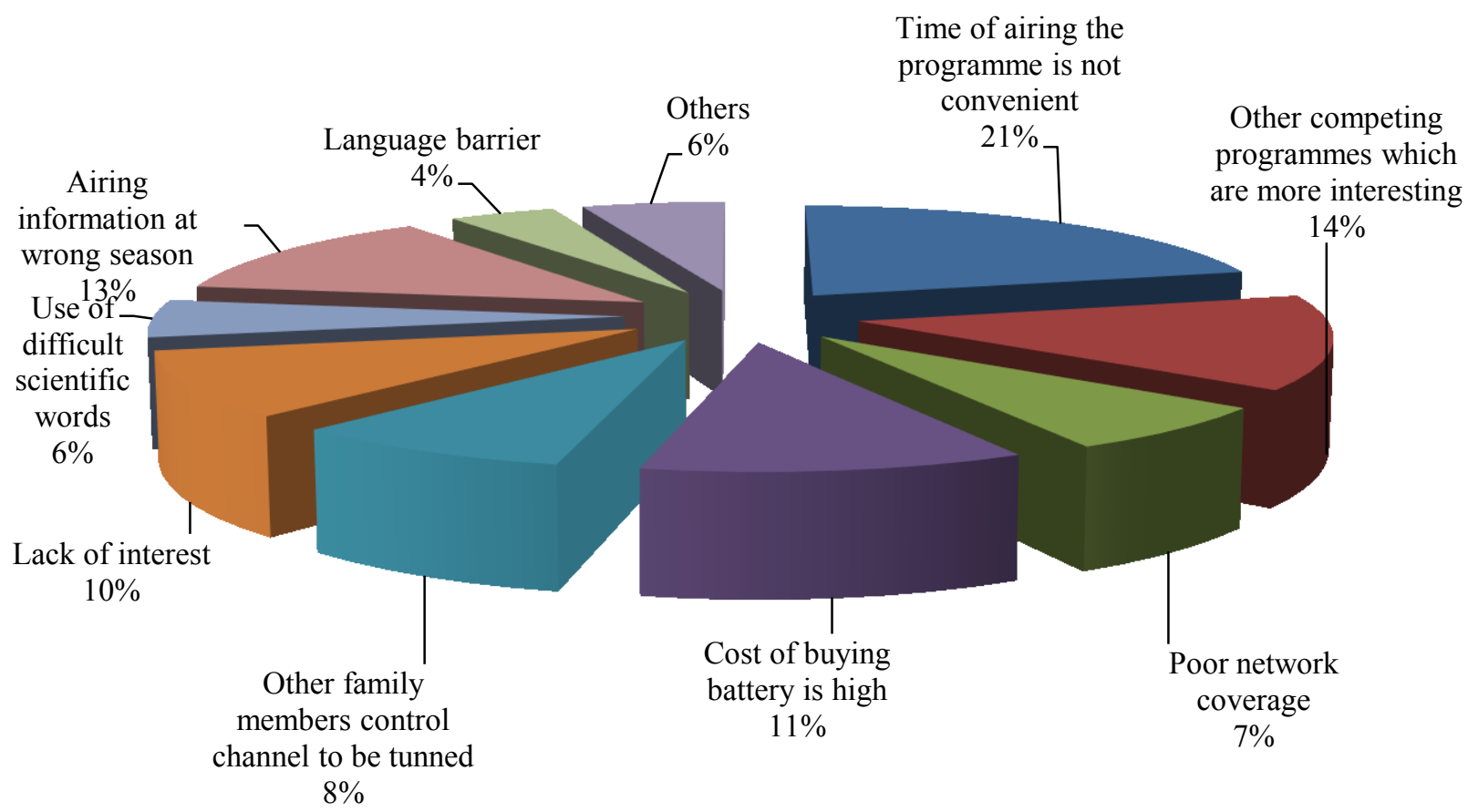

Figure 2. Challenges to listening to agriculture radio programmes

Source: own editing, 2013.

\section{Effective means of disseminating agricultural information to the youths through radio.}

The study seeks to find ways by which agricultural programmes can vastly be listened to by youths thus broaden their knowledge in agriculture hence their participation. Figure 3 below show the solutions that were captured from the youths for the challenges mentioned above. The major challenge mentioned was wrong timing of the agricultural programmes as most of the programmes are aired at time when youths were not able to listen to radio, as a solution to this the youths suggested repeat of agriculture programmes at different times of the day, this came up at $19 \%$. At $13.1 \%$ of the responses the youths felt that by involving them in content making, the programmes will be friendly to the youths as the issues of their concern will be captured well, at the same time by the fact that the youths will be getting information from their fellow youths through radio, this will make them gain interest on the discussion. 
At $11.9 \%$, the study revealed that use of agritips between other programme which are interesting to the youths can also make them gain interest to whatever message being passed thus will influence them to asking more questions about what has been said in brief through the agritip, this will make the youths much knowledgeable and will be able to implement what they have listen to. Show case of successful youths is also one of the ways by which youths can be influenced to take up farming as they will be able to hear about other youths who have

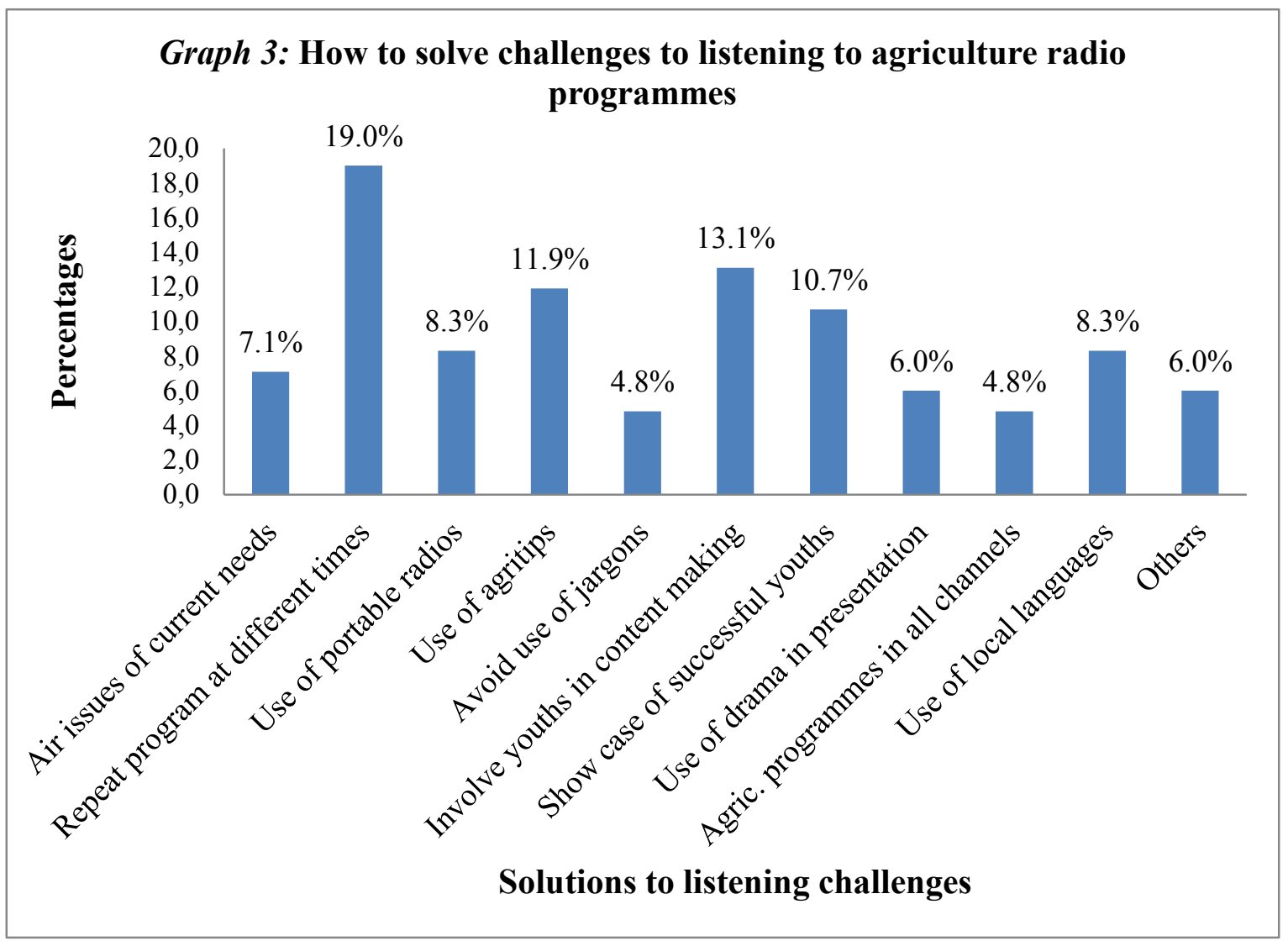

Figure 3. Solution to challenges to listening to agriculture radio programmes Source: own editing, 2013.

succeeded through agriculture; this gives them motivation to go into farming. The other two reasons which tie in the order of importance as in the graph above is use of portable radio and use of local languages; use of portable radio allows the youths to move with their radio to wherever they are going, hence increase their chances of listening to the agricultural programmes in a consistent manner, while use of local languages was supported as the youths felt that most of them listen to channels which advertise in their local languages thus if such programmes can be aired in such kind of community radio stations then it will be easy for them to listen to them. At $7.1 \%$, it is suggested that the agricultural messages in radio should be what farmers need at that time of the season for example if farmers are weeding then the messages should be those related to the period of weeding, this way it will make farmers to be able to implement what they are taught at the right time before they forget. At $6 \%$, it was found that youths get interest when the programme is presented in an interesting way like in drama form, thus to catch the interest of the youths, some of the agricultural programs should be presented in a drama form. Finally at $4.8 \%$, there is a tie on avoiding use of unfamiliar scientific languages "jargons" which youths cannot understand, and a suggestion that agricultural programmes should be aired in all radio channels. 
This will allow youths even those in areas where some of the channels could not reach to be able to benefit from those that they are able to tune. It also avail choices on which one to listen to which is the pride of the youths.

\section{Conclusions}

Effective radio programming is key in ensuring that the perception of youths is changed for them to take up agriculture as a meaningful economic activity. In the past as much as there has been radio programmes in the radio channels, to a major extent there has been many impedements to the youths listenership to such programmes. Through this study, we have realised that a major solution to this problem is airing agricultural programmes at a time when the youths are able to listen to the radio which in most case was at night but the study recommends repeat of the agricultural programme at diffent times of the day and use of agritips to ensure that the youths are able to have chance to listen to them. Many other ways have also been proposed under this study which are as described above.

\section{References}

1. Akugizibwe S., Amanya S., Kumaraki J.B.: Assessing the Potential of FM Radio Broadcasting in Promoting Rural Entrepreneurship in Sub Saharan Africa: A case study of the Rwenzori Region, Western Uganda. November 2011: http://torodev.co.ug/

2. Government of Kenya: 2009 Population \& Housing Census report: Kenya.

3. Government of Kenya: Particular Assets and Vulnerabilities of Rural Women within the Agricultural Sector in Kenya. National Agriculture and Livestock Extension Programme: August, 2009. http://www.nafis.go.ke/wp-content/

4. http://commons.wikimedia.org/wiki/File:Nyanza_Counties_-_Homa_Bay.jpg

5. Kathuri, N.J., Pals, D.A. (1993). Introduction to educational research Njoro, Kenya, Educational Media Centre, Egerton University.

6. Patrick O. Alila and Rosemary Atieno, 2006: Agricultural Policy in Kenya: Issues and Processes, A paper for the Future Agricultures Consortium workshop, Institute of Development Studies, 20-22 March 2006.

7. Proctor, F.J. and V. Lucchesi (2012) Small-scale farming and youth in an era of rapid rural change, IIED/HIVOS, London/The Hague.

8. Republic of Kenya, 2005: Economic Survey 2005. Government Printer, Nairobi.

9. UNDP-Kenya: Road to 2015: Driving the MDGs; Annual Report, 2009.

10. Woodard J.: Interactive radio for agricultural development projects: A toolkit for practitioners: FHI 360: December, 2012: ISBN: 089492-188-6. 